\title{
VISUALIZED ARGUMENTS; OR HOW TO PIERCE THE PERSUASIVE VISUALIZATION AND OTHER ARGUMENTS
}

\author{
Rachel Hann \\ School of Performance and Cultural Industries \\ University of Leeds \\ Leeds, LS2 9JT \\ UK \\ pcrnh@leeds.ac.uk
}

\begin{abstract}
This paper will present an argument towards establishing the act of threedimensional visualisation as a valid research methodology. An argument that is supported with evidence drawn from my own practical endeavours into the problem of accessibility and the 'persuasive visualisation'. This paper also documents the unique properties of the virtual material, focusing on its infinite malleability, in support of a secondary argument for the act of visualisation as a potential vehicle for discovery. The aforementioned evidence is drawn from a study on unrealised Utopian theatre architecture of the 1920's and 1930's.
\end{abstract}

\section{INTRODUCTION}

The process of collating, interpreting and practically realising a conceptual vision into a coherent three-dimensional form has proved a continuous fascination to me; from the humble Lego brick to the multidimensional possibilities of computer-based visualisation.

This paper is therefore the legacy of this infatuation, as it introduces my research into three-dimensional visualisation as a research methodology. This response is generated from a series of questions that were formulated during my practical investigations into unrealised Utopian theatre architecture. However, this paper focuses on one of these unrealised theatres. The new Meyerhold Theatre $(1930-1938)$ was the vision of the revolutionary Russian theatre director Vsevolod Meyerhold, assisted by his two architects Sergei Vakhtangov and Mikhail Barkhin. Meyerhold's vision was a prime example of my notion for Utopian theatre architecture. These were theatres designed to transcend the drama of the day in order to establish the drama of tomorrow. Yet it is this dichotomy which led in many cases to their unrealised status. Consequently, from an analytical point of view, in being unrealised their true nature remains frustratingly absent. I therefore propose that via an investigative visualisation, and the unique methodological processes thus enabled, a researcher is offered the chance to examine and possibly bridge this divide.

However, a problem arises when justifying the hypothetical elements (or paradata) that result from the process of formulating a hypothesised third dimension. The current methodological practice within the field of visualisation for research in the humanities, prioritises outcome-based research over possible processed-based alternatives. Consequently, this denies the process of realisation in favour of its realised product. The visualised outcome may fulfil the hypothetical goal of producing an experiential threedimensional reality. However, it is the nature of this outcome to persuade the reader into perceiving the visualised as a definitive 'truth', a phenomenon that is manifested by the 
associative qualities that three-dimensional visualisation shares with our perception of the world; and with its definitive perception being due to there being no apparent evidence of disparity with which to construct an argument. The critical academic study that took place in order to formulate the visualisation has been discarded in favour of its realised product. Even the most experienced of readers may struggle to dissect the hypothesised paradata from the factual metadata, as the two are conflated in order to establish a three-dimensional reality. Theatre historian Hugh Denard of the Kings Visualisation Lab describes this problem as the 'persuasiveness' of three-dimensional visualisation. This is a useful term, and one that Denard expands upon it in response to his teams work on the Theatre of Pompey;

"3D models and their derivatives (rendered images, animations, etc.) acquire a seductive 'persuasiveness' that can easily render invisible crucial distinctions between known fact, scholarly deduction, and creative - albeit educated-guesswork, and erode a sense of their provisional nature as research hypotheses." [1]

The persuasive visualisation is the perceived 'skin' of three-dimensional work; a skin designed to propagate the illusion of reality, so that a reader might experience and explore this unrealised or lost spaces in three-dimensions. The reader is able to gain an understanding and appreciation of how the space would have appeared via this unconscious illusion. This is an important pedagogical goal within three-dimensional research, as it is one that promotes awareness and the further understanding of lost or unrealised theatres. Richard Beacham, Hugh Denard and the KVL team are exploring the potential of this use as part of their latest project - Theatron 3 .

As we can see with the Theatron 3 visualisations, the skin remains intact as we experience the visualised theatre spaces. At chosen points we are offered a picture board with which to consider the source material that these hypothesised spaces are based upon. Yet, the state of knowledge these hypothesised structures represent is not made explicit to the reader. This is made particularly poignant by the level of imposed detail in the modelling of the visualisation, in an attempt to further develop this persuasive illusion.

\section{PIERCING THE PERSUASIVE VISUALISATION}

However, the issue remains that if these three-dimensional visualisations are to be independently scrutinised, the reader must have access to the scholarly process that informed these conclusions. In revealing the methodological process, the scholar is able to independently assess the researcher's conclusions, allowing the research to be recognised as a valid and reliable contribution. However, in disrupting this persuasive illusion what are the consequences for the pedagogical potential for these hypothesised structures? Furthermore, in attempting to provide access to the scholarly process are we denying the reader the experience of the three-dimensional form?

The choice to pierce this skin, instead of an altogether removal or slicing of it, is an attempt to tackle this dilemma. Although the skin is broken, the context with which it was set remains visibly intact. The reader is invited to explore beneath the perceived skin, towards the scholarly process, while still retaining an awareness of the threedimensional nature of the visualised outcome. In achieving this we are neither denying the process, nor the outcome. We are establishing a text, through which a reader can both critique, and experience, the concluded form. 
This proposed 'piercing of the skin' exposes the layers of information below the surface. Information that documents the path, from the conceptual sourced material, to an interpreted three-dimensional environment. This is made possible by the grouping of selected elements of information, (i.e. one group may represent all the primary technical drawings) the reader is then free to select these groups via informational layers. These layers can either appear visible or hidden, dependant on how the reader wishes to organise the data. Equally, the layers enable the reader to directly identify how information - such as a ground plan - was translated, extrapolated and incorporated in order to form a hypothetical third-dimension. In practice these layers facilitate a reader's access to the critical analysis via the integration of abstract elements into the visual language of the visualisation. These abstract elements can manifest themselves in various forms:

(The following examples are taken from a visualised study on the Sohn Theatre, which was home to The Meyerhold Theatre Company from 1922 to 1931.)

\section{Integration of Metadata}

The diagrammatic items of metadata are directly positioned within the architecture of the visualisation, with an opacity value of $60 \%$. This enables the reader to gain an overview of how the visualised outcome relates to the sourced metadata, without denying the reader the experience of the extrapolated data in three-dimensions.

\section{A Reference System}

This works by selecting the layer of information which relates to a single item of metadata. The wire frames of its related hypothesised forms are then highlighted, with the opacity value of any applied textures set to either $60 \%$ or $0 \%$. (Dependant upon how the reader wishes to view the data in relation to the visualised outcome.) This enables the reader to independently piece together the lineage of these elements, by identifying how they were interpreted and extrapolated from

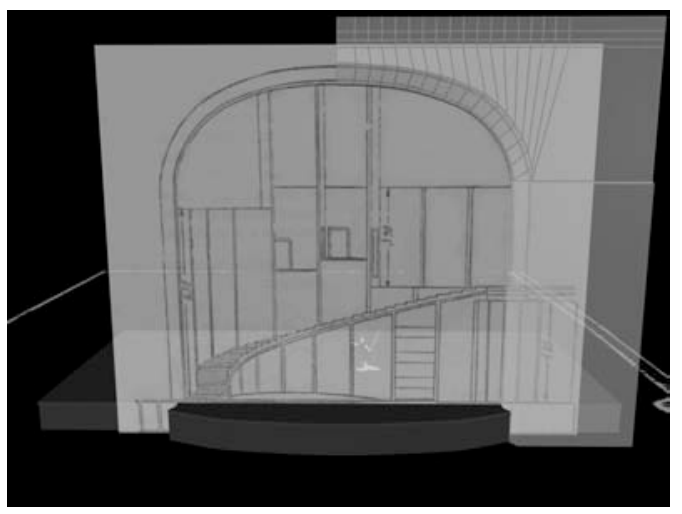
the two-dimensional references.

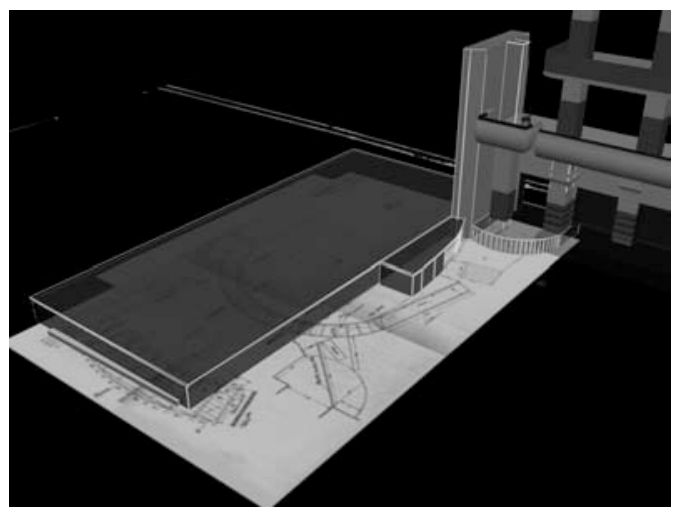

Metadata windows 
The available metadata arrives in a multitude of different forms. These may not be suitable for integration into the architecture of the visualised outcome. For example, on visiting the Sohn Theatre the British academic André van Gyseghem describes it as being akin to a meeting hall in both a philosophical and practical sense. [2] However, as a textual description it has no dimensional axes with which to position it at a specific point within the architecture of the visualisation. Therefore, each

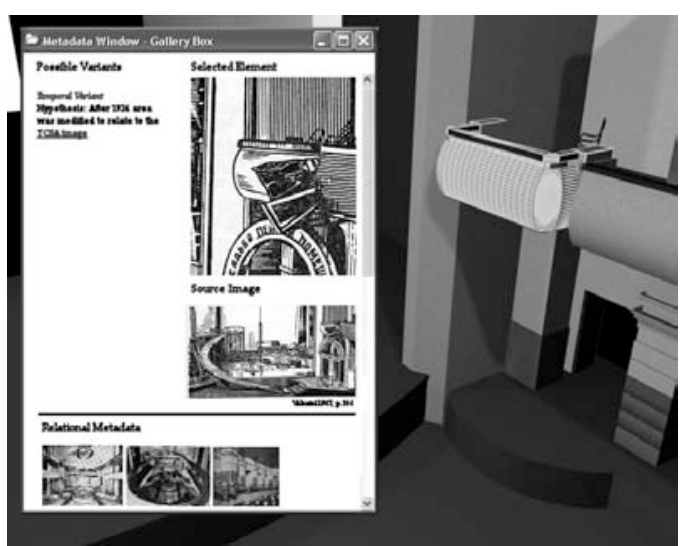
architectural element has a window of information which pops up when requested by the reader. This window details a series of different values that influenced the interpretation of the selected element. Firstly, it displays any relevant items of metadata that are not integrated into the visualisation itself, (i.e. illustrations, sketches, textual references, etc.) with each of these being divided up into specific areas of relevance. When selected they highlight the translated form to which it relates to by employing the above reference system. The window also notes any other integrated items of metadata which influenced the subjects form (via a hyperlink to the relevant parallel window). The window also provides a detailed explanation of the element's function and significance within the theatre.

\section{Visual Arguments: Alternative hypotheses}

The persuasiveness of the visualised outcome actively prevents the reader from assessing how the researcher constructed their arguments, by distancing the visualised from any evidence that might counter its finalised form. One possible way of confronting this issue would be to, from the outset, include any discarded and/or alternative hypotheses within the architecture of the visualisation.

The inclusion of these conflicting hypotheses documents the decision-making process for the reader. They are invited to assess the work via the comparative analysis enabled between these alterative hypotheses and the visualised outcome (or any other possible variants). Within my research this manifests itself as an alternative visual argument, assessable as a distinct layer of information (which the reader is able to select whether they are visible or hidden.) These arguments highlight any conflict or disparity encountered during the visualisation process, normally providing an alterative to an architectural element's form or position. These are then referenced back to the appropriate conflicting sets of metadata, via the previously described methods of referencing and associative metadata windows.

The new Meyerhold Theatre is a good example for demonstrating how these visual arguments provide an insight to the researchers methodological process. When in 1930 Meyerhold was provided with funds for a renovation of his dilapidated Sohn Theatre, he adamantly demanded nothing less than a completely new building. The result of this was three variants, each a development of the last, with the third being the pragmatic realisation of the idealised second. Construction began in the mid 1930s until, after a drawn out and problematic process, in 1938 Meyerhold's Theatre Company went into liquidation and the building remained incomplete. A few months later Meyerhold was arrested, accused by the Stalinist government of several offences; including 
espionage, mysticism and a neglect of Socialist Realist ideology. His wife and leading actress, Zinaida Raikh, was brutally murdered by an unknown assailant at their family home on the $15^{\text {th }}$ July 1939 . With no knowledge of his wife's fate - having been held by the authorities since his arrest - on the $2^{\text {nd }}$ February 1940, Vsevolod Emilevich Meyerhold was executed by firing squad, as an enemy of the soviet state. Fifteen years later, in 1955, the soviet government issued a decree absolving Meyerhold of any misconduct. However, only ten months after Meyerhold's death, subsequent to an extensive redesign by architect D.N Chechulin, his new theatre opened as the Tchaikovsky Concert Hall, which still stands today as a symbol of Meyerhold's stolen legacy.

In terms of visualising this lost theatre, its incomplete physical realisation provides us with data from several primary sources; the three variants, photographs of the building site and the 1940 redesign. However, none of these sources supply all the required information, instead they present a series of different variations on the same concept. Therefore, it was necessary to translate, incorporate and modify the information from each of these conflicting sources in order to argue the most probable form for the three-dimensional visualisation.

The critique of this methodological process is a practical one. The argument against a variant may have become apparent at an early stage of its formulation. Therefore, the time spent visualising this discarded variant is arguably counter productive to the production of the visualised outcome and/or answering any research questions. In addition to this, a consideration must be given to what level of detail (and accuracy) is necessary for the articulation of these conflicting arguments. So that these might be recognised as a legitimate variation and not a result of an error within the process of construction.

\section{AN INVITATION FOR EXPERIMENTATION: THE PLAYFUL NATURE OF THE VIRTUAL MATERIAL}

The act of visualisation - be it with wood, steel or virtual material - is the investigative process of translating the collated metadata and extrapolating these previously alien datasets into a coherent three-dimensional form. As discussed earlier this information can arrive in a multitude of different forms, however, due to the nature of an unrealised structure few will detail the exact information required for the $\mathrm{X}, \mathrm{Y}$ and $\mathrm{Z}$ axes. Consequently, as the visualisation develops and the interpreted metadata sets begin to interact, they inform and evolve one another via the 'playful' interaction enabled by the software, in this case AutoDesk's 3D Studio MAX 2008. This process formulates the required $\mathrm{X}, \mathrm{Y}$ and $\mathrm{Z}$ axes information via this 'evolutionary process of play'. The London Charter defines this information exchange as a dependency relationship, "a dependent relationship between the properties of elements within $3 D$ models, such that a change in one property will necessitate change in the dependent properties." [3] However, this relationship eclipses a relational dependant change, as the materials unique properties invite the researcher to play with the information in a manner that was previously impossible. The elements of metadata, which were formerly alien to one another, can now interact; they are on a continuous cycle of evaluating and justifying their relational properties. This continuum of evaluative discussion is unique to the process of visualisation, due to an almost infinite malleability of the virtual material. Whereas, physical modelling materials (wood, plastic etc.) have a fixed set of proprieties allowing them to be modified to a predetermined degree, the virtual material 
can be modified again and again (and again) without the material degrading, distressing or becoming unusable. Therefore, the researcher is invited to investigate potential variants without concern for the predetermined limitations of the material's properties. These translated elements of metadata, which now share a common form as a threedimensional virtual material, are now able to directly communicate with each other as a result of this process. Whereas, with physical visualisation methodologies the translation matrix is the researchers cognitive thought processes - although, the act of visualisation does not replace this - the playful interaction offered, via the infinite malleability of these virtual material, can significantly aid the researcher in this extrapolation process. In addition to this, a virtual material can intersect with another without affecting the properties of either. Consequently, there can be several virtual objects inhabiting the same space.

The pseudo nature of the virtual material's physicality enables the researcher to formulate a series of variants on the same object (or other objects) within the same contextual space. For example, any conflict relating to an items positioning identified during its visualisation, could be articulated by a series of visualised arguments. These would document how the alterative possibilities would fit within the context of the space, allowing the reader to assess their plausibility. Whatever the case, this nonreaction between the intersecting objects combined with the infinite malleability of the material invites a researcher to experiment with a variety of forms and variations. To a degree which would otherwise be time consuming, expensive and/or counter productive with physical visualisation methodologies.

\section{THE VIRTUALLY CONCLUDED ARGUMENT}

The access granted by implementing these methodological processes, enabling the transparency of any research outcomes generated, acts to identify the epistemological status of the research. The outcome acknowledges that any conclusions drawn from the visualisation are directly relational to its research process. The authenticity of the visualised comes not from the ease of exploration the three-dimensional form necessities, but from the recognition of the research processes undertaken. Much like a hand drawn sketch or illustration, there is an intrinsic awareness of epistemological status of the knowledge presented from the outset. The conclusions are therefore recognised to be reliant upon the access granted from assessing the research's rigour, rather than the visualised outcome being perceived independently and therefore alluding to a definitive answer.

Consequently, if we acknowledge that the visualised argument is a result of its research processes, it is not irrational to propose that the researchers practical exploration of the metadata may produce arguments that would have otherwise remained dormant or undiscovered. The unique interaction offered (to the researcher), due to properties of the virtual material - and by acknowledging how the visualised element was collated, interpreted and incorporated to form a coherent whole - may instigate (and validate) the formulation of new insights that physical (re)construction would negate. The act of visualisation can therefore be recognised as having actively contributed to the epistemological consciousness of the subject, thus providing clear evidence of the potential and importance of investigative visualisation as a vehicle for discovery. These virtually concluded arguments are therefore a phenomenon of this methodological process. The unrestricted experimentation, enabled by the evolution of the material, is a key component in the generation of these conclusions. An interaction 
that is unique to computer-based three-dimensional visualisation. In inviting the researcher to modify, re-position, remove or add elements to the visualisation, without any negative affects to the quality of the material or imposing a limit on the potential for its future modification, promote computer-based visualisation as a vehicle for discovery in a manner which is unavailable within physical (re)construction. By ensuring the transparency of the knowledge processes and critical evaluation undertaken by the researcher, we are enabling these virtually concluded discoveries to be academically scrutinised. This in turn validates any conclusions as a reliable contribution. In acknowledging their provisional epistemological status, this positions the knowledge as being virtually concluded, and thereby re-affirming the visualised product as an informed argument, not as a definitive 'truth'. Bernard Frischer and Philip Stinson acknowledge that the process of visualisation may indeed generate new insights by noting;

"[V]irtual reconstruction (not unlike physical reconstruction in archaeology) is a tool that can be used, by experts, to generate new discoveries and insights and, by the general public, to understand a site more quickly and effectively.” [4]

Consequently, the visualised outcome provides us with the same vehicle for discovery that a physical (re)construction would. Moreover, it may become possible for the visualised construct to assume the cultural status of a physical (re)construction, as Denard states, "[v]irtuality, by default, is the primary reality since it is the only "reality" in which the information structure and appearance of the whole objects now exists." [5] Therefore, in practical terms a three-dimensional visualisation may represent not only the researcher's argument for a prior/unrealised structure, it can also provide the academy with a model for investigation, and a flexible, autonomous tool for learning. The visualisation of the new Meyerhold Theatre provided an exemplar of this virtually concluded phenomenon.

\section{DESIGNING A PRODUCTION AXONOMETRICALLY: MEYERHOLD'S POSITION}

In order to best articulate the significance of this discovery, it must first be contextualised within Meyerhold's vision for his unrealised dramaturgical practice.

The third principle for the new theatre, as detailed by Vakhtangov and Barkhin, states that the audience should perceive the production axonometrically, both from above and the side. At first this may seem a somewhat impractical demand, however, Vakhtangov and Barkhin offer an articulation of what the actuality of this may have been like, by allowing us a glimpse of Meyerhold's preferred directorial position; "he personally preferred to watch his productions from a doorway in the stalls close to the stage, or from a side seat in the upper circle." [6.1] Meyerhold had lost faith in the end on arrangement of the Moscow theatres. In order to realise a new soviet drama the audience and action must be as one, (principle one) he rejected the two-dimensional arrangement of the baroque influenced theatres, so that the action and spectator might inhabit the same architectural space. As Vakhtangov and Barkhin state,

"[Meyerhold] wanted to make it possible for the spectator to view the actor in all his plasticity and action in the full range of its spatial development. Movement was 
intended to flow not merely from left to right, but backwards and forewords as well, bisecting the stage."[6.2]

In viewing his productions from the wings Meyerhold felt an awareness of the actors physicality, their plasticity and their form. The illusion of reality was broken in favour of the recognition of the actors as workers; the stage was no different from the factory floors of Moscow. By viewing the production in this manner Meyerhold felt, that as a spectator, he gained a sense of the theatrical production's mechanics, provoking a continuous awareness of the falsified nature of the presented theatre. This was of course diametrically apposed to what we might term as, the realistic movement, influenced heavily by the early work of Meyerhold's teacher and mentor, Konstantin Stanslavski. Meyerhold argued that this improved appreciation of the actor's plasticity invokes a conscious acknowledgment of the spatial relationships between the other actors, the scenographic constructions and finally, the architecture itself. Prof. Edward Braun, the leading English language scholar on Meyerhold's work, describes Meyerhold's ventures into realising this axonometric viewpoint for the productions of Lady of the Camellias (1936) and List of Assets (1931);

"Most of the actors movements, following the line of setting, were diagonal, ensuring the spectators a three-quarters view which was more plastic and free from masking, even in extreme close up. Thus, the production was conventionally representational yet conceived in the three-dimensional terms more commonly associated with the open stage." [7]

Although, it must be kept in mind that the employment of the diagonal proscenium line was primarily a response to the limiting width of the proscenium opening at the Passage Theatre (the Ermolova Theatre; the Meyerhold Company home during the construction of the new theatre, 1931 - 1938). It does however present us with an example from which we can hypothesise the practicalities of Meyerhold vision for a new dramaturgical practice.

It was during the visualisation process that I became aware of a prominent element within the architectural layout of the new theatre. One that had no contextual information with which to legitimate the positions described prominence. Located on one of the primary items of metadata - an original ground plan of the third variant sourced from The Bristol Theatre Collection - there were two dotted lines emanating from stage left. The ends of which pincer the extremities of the two main stage revolves. An indication that whatever is located towards stage left held a significant status within the dynamics of the space. No other item of metadata - textual, pictorial or diagrammatic - shed any further light on this architectural element's function and/or significance.

However, my visualisation of the new theatre provided me with the opportunity to examine and investigate the nature of this position. The relational information dictated that these dotted lines were referring to a section located just off

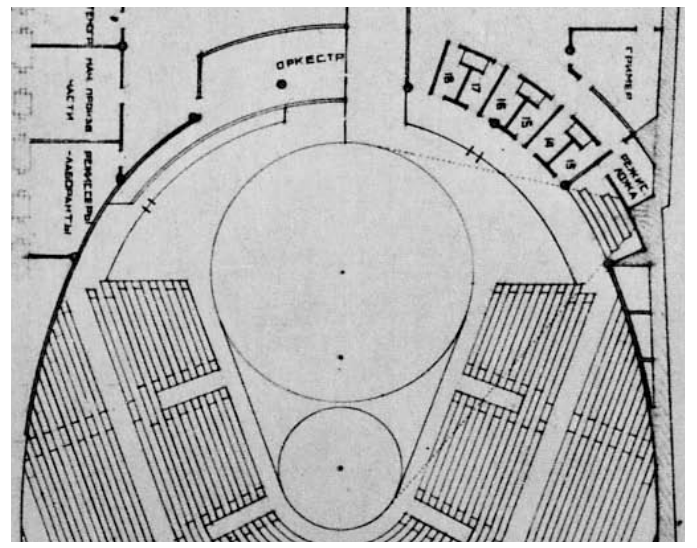


the second level walkway, above the entrances that had been designed specifically for motor vehicles to directly enter the main space. The series of rectangular objects located at this point were hypothesised to be an extension of the auditorium seating, due to their similarity with the lines that were interpreted to form the auditorium seats. Although, due to Meyerhold's belief that the auditorium should be free from division, the hypothesis that this section was a reserved section of seating, or box, can be discounted. Which provokes the question; why were their seats positioned at this point and what (or who) were they for?

Via the three-dimensional form of the hypothesised visualisation we, as researchers, are invited to analyse the structure in a manner that numerical, textual or twodimensional images negate. The image below documents the view offered from this phantom position. What strikes us is that from this position close to $75 \%$ of the structural space is in full view, offering us a vantage point that invokes a full appreciation for the spatial dynamics of the theatre.

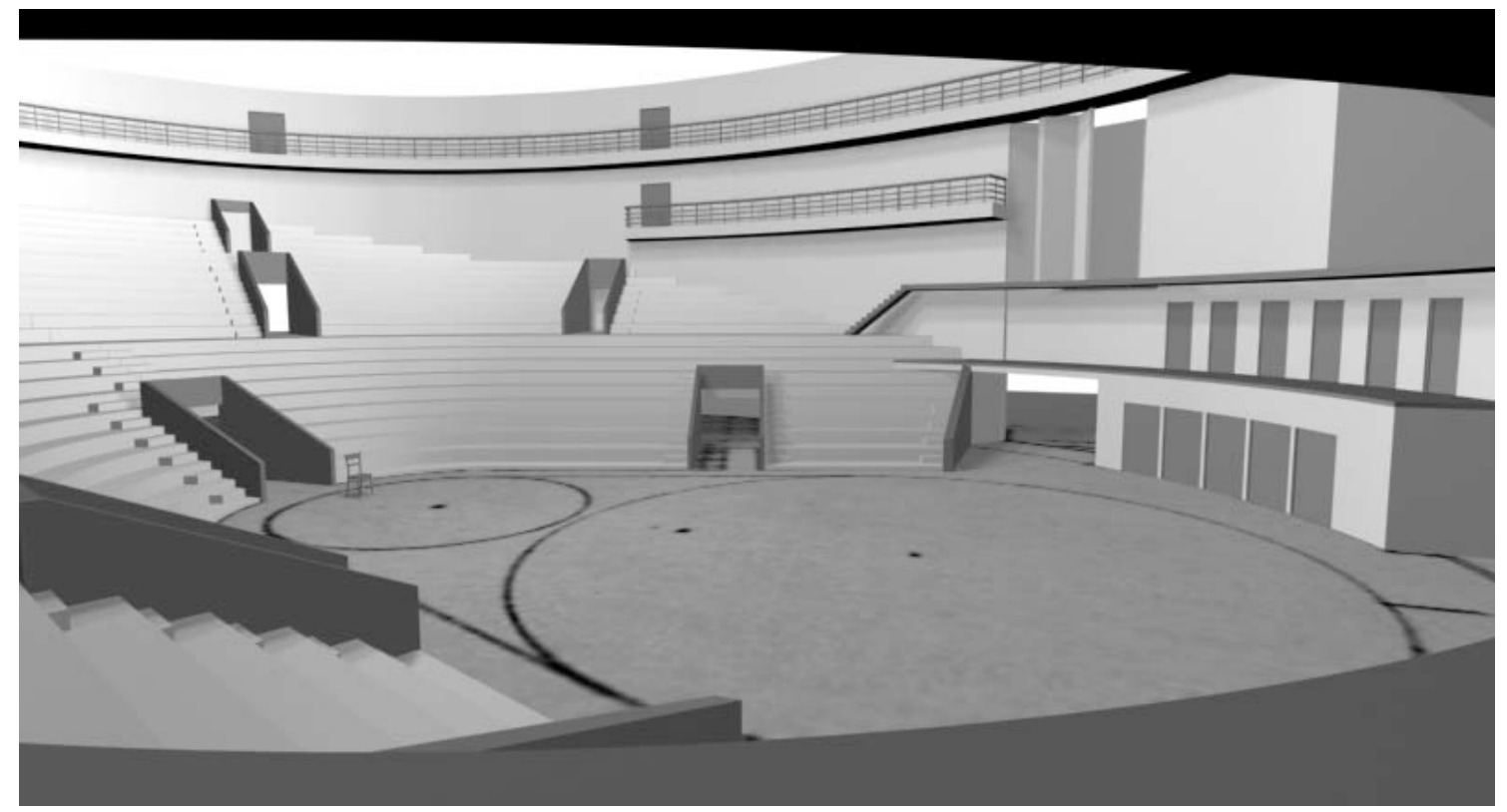

The authority of this position is self-evident, however, the significance of this authority becomes apparent when combined with an awareness of Meyerhold's axonometric dramaturgical vision. From this position an individual could command and control the entirety of the given architectural space. The resulting production would have had the potential to employ all the dimensional axes of the space, no longer governed by the pre-determined frontal perspective of the proscenium frame and its derivatives.

From this a hypothesis emerges: that this position had been designed specifically for the formalisation and practical implementation of Meyerhold's vision for a new dramaturgical practice. From this point he would have directed the unrealised productions of 'I Want a Child', 'Macbeth' and 'Boris Godunov'. The multitude of levels, as documented in the above image, lends itself to the emersion of the audience Meyerhold had envisioned for the production of 'I Want a Child'. The action would have taken place from every conceivable direction and level. In achieving this Meyerhold had anticipated that the audience would have behaved more in the manner of 
a seated crowd - such as that which you find at a sporting event - than the silent, appreciative audiences that nightly filled the Moscow Art Theatre. However, this is a hypothetical proposition for Meyerhold was denied, in the most extreme manner, the opportunity to fully develop these ideas.

Nevertheless, what the visualisation offers is an otherwise undiscovered insight into the practical execution and operation of his new theatrical form; an insight that was formulated due to the demanding exactitude of the process, combined with the virtual material's unique qualities and the unheralded ease for experimentation which these qualities enable. By translating the metadata into a form that mimics its intended physical reality - rather than an alien numeral or two-dimensional one - this invites a performativity, that is to say the manner with which a three-dimensional model enables us to relate to the space employing the four dimensions, which allows us an insight into the space that numeral and two-dimensional forms of visualisation negate. There is no record of this prominent position having been formulated as a specific point from which to direct, which maybe due the small amount of scholarship on Meyerhold's new theatre. However, the process of computer visualisation has facilitated and generated this argument, an argument that, prior to the research process was undocumented. The act of three-dimensional computer visualisation has therefore provided evidence for a rigorous and structured analytical evaluation of Meyerhold's theatrical proposition.

\section{References}

[1] DENARD, H: At the Foot of Pompey's Statue: Reconceiving Rome's Theatrum Lapideum in Bowman, Alan K. \& Brady, Michael (eds) (2005) Images and Artefacts of the Ancient World: Oxford :Oxford University Press

[2] VAN GYSEGHEM, A: Theatre in Soviet Russia: London: Faber and Faber LTD, 1943.

[3] London Charter Initiative 2006: http://www.londoncharter.org/

[4] FRISCHER, B and STINSON, P: Interpreting the Past: Heritage, New Technologies and Local Development Proceedings of the Conference on Authenticity, Intellectual Integrity and Sustainable Development of the Public Presentation of Archaeological and Historical Sites and Landscapes: Ghent, East-Flanders: September $11^{\text {th }}-13^{\text {th }} 2002$.

[5] DENARD, H: Virtuality and Performativity: Recreating Rome's Theatre of Pompey Performing Arts Journal: Vol.24 No.1: pp.25-43 2002.

[6.1] BRAUN, E: A Theatre for Meyerhold: Theatre Quarterly: Volume II Number 7, July-September 1972: pp. 69-73

[6.2] ibid pg. 70

[7] BRAUN, E: Meyerhold: A Revolution in Theatre: London: Methuen 1995. 